\title{
European Society for Medical Oncology Invests in the Next Generation of Asia-Pacific Oncology Leaders
}

Leadership /'li:də]rp/

NOUN

mass noun

1. The action of leading a group of people or an organization.

Retrieved from http://english.oxforddictionaries.com/ leadership.

The European Society for Medical Oncology (ESMO) is a Europe's leading nonprofit medical oncology organization. Since its creation in the 1970s, the organization and its membership have grown on a global scale, with $>25,000$ members worldwide. Despite its European name, the ESMO membership includes a broad range of health professionals, researchers, and patient advocates from around the world. Twenty-five percent ( 6000 members) of ESMO's membership resides within the Asia-Pacific region. With this in mind, the ESMO has focused on several activities to specifically address issues unique to the Asia-Pacific region. In November 2019, ESMO conducted its inaugural ESMO Asia Leaders Generation Programme (LGP). Modeled on the European Annual ESMO LGP launched in 2016, this fully ESMO-funded program was specifically targeted at potential emerging leaders within the Asia-Pacific region. This Editorial is directed to provide readers and especially potential leaders, an overview of this ESMO initiative from a participant's and mentor's perspective.

\section{Participant's Experience}

I was fortunate to be selected to participate in the ESMO Asia LGP 2019. A total of 16 participants, aged between 31 and 45 years, came from 15 different countries in the region. Clinical subspecialties included medical oncology, radiation oncology, and surgical oncology. Over 4 days, we immersed ourselves in the world of ESMO, learning about ESMO's structure and various divisions, what ESMO has to offer our colleagues and us, and how to improve our professional skills (leadership and communication training). The experience was eye-opening and rewarding. New friendships were forged among each other and with key ESMO members and mentors who generously donated their time.

Two days was dedicated to ESMO itself, focusing on an overview of ESMO, including ESMO's role in Asia, society-related activities, and individual and organizational challenges that the LGP participants might encounter.

Within my current role/s, what resonated with me was ESMO's commitment to education. Aside from congresses and summits, educational activities include medical student courses (aimed at attracting students to the field of oncology), fully funded preceptorship, and as a prelude to the ESMO examination, the Annual ESMO Academy. Alongside this, the ESMO offers free access to members to an encyclopedia of presentations, webinars, and other resources through the OncologyPRO online platform (https://oncologypro. esmo.org). Career development is fostered, not just through programs such as the LGP, but also through ESMO fellowships, and groups such as the Young Oncologists Committee and Women for Oncology which assist with network building and linking to potential mentors.

We had a brief, albeit fascinating, introduction to gender medicine from our current President, Prof. Solange Peters, an aspect of cancer care that is often ignored in clinical trials, and took a deep dive into the three ESMO journals (Annals of Oncology, ESMO Open, and IOTECH). In this day and age of cost-effectiveness and appropriate resource allocation, understanding and applying the ESMO-Magnitude of Clinical Benefit Scale and understanding biosimilars and their role were critical and something to share with my colleagues back home. The topic of biosimilars was of particular relevance given recent approval for reimbursement of several antineoplastic therapeutic agents in the Asia-Pacific region.

The remaining 2 days was designed to hone the participants' personal and professional skills. The first of these days addressed presentation skills and media interactions. This was my first exposure to media training, which is rarely addressed as part of any core medical curriculum. Each participant had an opportunity to get in front of the camera. Despite our initial trepidation, our confidence grew (along with the complexity of the scenarios!) as the day progressed and we were able to put theory into practice.

The final day of the LGP addressed specific leadership and management skills and styles and how to use these to get the most out of one's team. The final day of the LGP addressed specific leadership and management skills and styles and how to use these to get the most out of one's team. Whilst clearly each of us had our own leadership style, perhaps the key learning points for the group were that there is not necessarily one perfect leadership style, the value of adaptability and the importance of selfreflection including the cycle of continual feedback and reflection.

As the group got to know each other, we discussed the often significant differences in healthcare across the Asia-Pacific region and how we could potentially collaborate. Overall, I found the LGP to be a valuable and rewarding 
experience, and I would encourage others to disseminate this information and to apply. The faculties were incredibly generous with their time and advice, not to mention the fantastic organizers. On behalf of the LGP-Asia Class of 2019, we extend our gratitude to ESMO for this wonderful initiative and opportunity.

\section{Mentor's Perspective}

I have experienced this exceptional program from two different perspectives: I was one of the five participants from Asia for the ESMO LGP 2018 where Europeans along with Asian candidates were selected to be part of this program in Lugano at the ESMO Headquarters. We had training sessions as described above from the superheroes of the oncology fraternity, hosted in a fabulous venue with terrific company of Friends! This provided an optimum soil for the potential leaders to transform into true leaders and a great platform to get involved in ESMO activities. Participants are given the opportunity to become part of the extended ESMO family: I was invited to join the ESMO Sarcoma Faculty in line with my core area of interest. I contributed to successive ESMO Asia Congresses as a faculty member and invited to write for the ESMO Perspectives digital magazine. We discussed the importance of this program, and everyone agreed that if this program could be conducted in Asia, then the benefit could be available to more participants.

It was overwhelming to see ESMO in action and soon this was materialized with the launch of the ESMO LGPASIA in Singapore, taking place prior to the ESMO Asia congress. This time I was provided with a bigger responsibility of mentoring the bright next generation leaders. The best leaders not only help to develop the very best of us, but they advocate our future! The best leaders not only help to develop the very best of us, but they also advocate our future!
My message to all the young oncologists in their early career is to explore such opportunities under the umbrella of ESMO to enhance their careers. A leader is one who knows the way, goes the way, and shows the way to others and I hope that many budding oncologists will enjoy this wonderful journey!

We deeply acknowledge the valuable inputs provided by the following ESMO members, Evandro de Azambuja, Ravindran Kanesvaran, Katharine Fumasoli, and Venessa Marchesi.

Rachel Wong ${ }^{1,2}$, Jyoti Bajpai ${ }^{3}$

${ }^{1}$ Department of Oncology, Eastern Health, Box Hill, Australia, ${ }^{2}$ Department of Oncology, Monash University, Eastern Health Clinical School, Box Hill, Australia, ${ }^{3}$ Department of Medical Oncology, Tata Memorial Centre, Homi Bhabha National Institute, Mumbai,

Maharashtra, India

Address for correspondence: Dr. Jyoti Bajpai,

Room 1115, $11^{\text {th }}$ Floor, Homi Bhabha Block, Tata Memorial Centre, Parel, Mumbai - 400 012, Maharashtra, India. E-mail:dr_jyotibajpai@yahoo.co.in

Submitted: 18-Jan-2020

Accepted in Revised Form: 25-Feb-2020

Published: 24-Apr-2020

This is an open access journal, and articles are distributed under the terms of the Creative Commons Attribution-NonCommercial-ShareAlike 4.0 License, which allows others to remix, tweak, and build upon the work non-commercially, as long as appropriate credit is given and the new creations are licensed under the identical terms.

\begin{tabular}{|l|l|}
\hline \multicolumn{2}{|c|}{ Access this article online } \\
\hline Quick Response Code: & Website: \\
\hline & www.ijmpo.org \\
\cline { 2 - 3 } & DOI: \\
\hline
\end{tabular}

How to cite this article: Wong R, Bajpai J. European Society for Medical Oncology invests in the next generation of Asia-Pacific oncology leaders. Indian J Med Paediatr Oncol 2020;41:7-8. 